\title{
In defence of constitutive rules
}

\section{Corrado Roversi ${ }^{1}$ iD}

Received: 30 April 2021 / Accepted: 21 September 2021 / Published online: 20 October 2021

(c) The Author(s) 2021

\begin{abstract}
Although the notion of constitutive rule has played an important role in the metaphysical debate in social and legal philosophy, several authors perceive it as somewhat mysterious and ambiguous: the idea of a specific kind of rules that are supposed to be "magically" constitutive of reality seems suspicious, more a rationalistic fiction than a genuine explanation. For these reasons, reductionist approaches have been put forward to deflate the explanatory role of this notion. In this paper, I will instead try to defend constitutive rules. My thesis is that the notion of constitutive rule is explanatorily helpful because it gives a complete account of an important phenomenon in the social and legal domain, namely, that of artifactual entities endowed with statuses that can have emergent normative properties. Conceiving of these entities as rule-constituted artifacts is an important part of what H. L. A. Hart called "the internal point of view" toward law, and for this reason constitutive rules should be included in an explanation of that point of view as an integral part of the life of institutions. The structure of my argument will be as follows. First, I will provide an example of an important phenomenon in the internal point of view, namely, the fact that individuals can have normative reactions not about the specific regulation of an institution but about its underlying purpose and rationale-what in the legal domain is called the ratio of a norm. Then I will identify two reductionistic approaches on constitutive rules. The first approach is exemplified by Brian Epstein's idea that the phenomena explained by constitutive rules are better explained in terms of metaphysical (grounding/anchoring) relations. The second kind of reductionism is instead exemplified by the idea (held by several authors, among whom Alf Ross, Riccardo Guastini, Frank Hindriks, and Francesco Guala) that the phenomena explained by constitutive rules can be accounted
\end{abstract}

I have presented previous versions of this paper at the Surrey Center of Legal Philosophy Seminars and at the 12th Biennial Collective Intentionality Conference: Social Ontology 2021, held at the University of Neuchâtel. I am thankful to all the colleagues who provided valuable feedback on those occasions, and also to two anonymous referees for this journal, whose helpful comments were instrumental in improving the paper.

$凶$ Corrado Roversi

corrado.roversi@unibo.it

1 Department of Legal Studies, University of Bologna, Bologna, Italy 
for in terms of regulative rules plus a certain terminology. I will try to show that neither of these approaches can explain normative reactions to the ratio of an institution from an internal point of view: While the first cannot explain the fact that the reaction is strongly normative, the second cannot explain the fact that the reaction is about the ratio of a normative entity. Constitutive rules can instead explain both things and should be preserved as an important notion for the analysis of institutional ontology. By way of constitutive rules we create something: immaterial, rule-based institutional artifacts that can have emergent normative properties.

Keywords Constitutive rules · Metaphysical grounding · Social ontology · Institutions · Institutional statuses

\section{Introduction}

The notion of constitutive rule has played an important role in the metaphysical debate in social and legal philosophy. Drawing on Czesław Znamierowski's theory of constructive norms, Ludwig Wittgenstein's observations about the rules of games, John Rawls's views about the "practice conception" of rules, and H. L. A. Hart's concept of secondary rules, legal and social philosophers such as John. R. Searle, Amedeo G. Conte, Gaetano Carcaterra, Neil MacCormick, Frank Hindriks, Andrei Marmor, Jaap Hage, among many others, discussed the consequences of this notion for a better understanding of social institutions and tried to extend its explanatory power by adapting it to the legal domain. However, the same notion has been perceived by many as somewhat mysterious and ambiguous, to the point of being useless, and indeed much of the discussion on constitutive rules over the past thirty years has been a discussion about possible ways to reduce the phenomena this notion is aimed at capturing to something less obscure. On the one hand, the sense was that constitutive rules are not peculiar rules, but can be traced to other kinds of rules or even to a general feature of normative phenomena. On the other hand, the idea of rules that are magically constitutive of social reality seemed to many to denote a rationalist fiction rather than a genuine explanation. For these reasons, reductionist approaches have been put forward to deflate the notion's explanatory role.

In this paper, I will offer a defence of constitutive rules. My thesis is that the notion of constitutive rule is explanatorily helpful because it gives a complete account of an important phenomenon in the social and legal domain, namely, that there are entities endowed with statuses that are artifactual. Seeing these entities as endowed with an artifactual status that is rule-constituted is an important part of what H. L. A. Hart calls the "internal point of view," the understanding and adoption of which, in Hart's view, is necessary to explain law and other practices derived from social rules. My strategy in support of this thesis will be as follows. In Sect. 2, as a sort of in vitro case study, I will present an instance of a phenomenon that is meaningful from the internal point of view. Then, in Sects. 3 and 4, I will present two kinds of reductionism about constitutive rules that are complementary and that, taken together, completely deflate the notion, but I will show that these two reductionist strategies cannot account for the case study, whereas constitutive rules can. My conclusion will be that constitutive 
rules are explanatorily more powerful than the two counterarguments. This does not in itself show that constitutive rules are an inevitable element of the internal point of view, because the two counterarguments could be drawn from a "bad lot" and another powerful criticism could be available. Still, the discussion will show that the best explanation of the case study must at least include the conceptual features of constitutive rules. Hence, even though it is possible that constitutive rules are not sufficient to explain institutional phenomena, I will argue that they are at least a necessary element in such an explanation.

Before proceeding, there are a few important points about my approach I ought to clarify (see also Roversi, 2019). The first is that, in talking about constitutive rules, I assume a notion that could be different from the one the reader versed in legal philosophy or social ontology has in mind. I do not think, for example, that constitutive rules must have a "counts as" structure ("X counts as $\mathrm{Y}$ in context $\mathrm{C}$ "): This is the formula that J. R. Searle has often cited as being characteristic of constitutive rules and that, according to a common misunderstanding of his view, many think should be found in all constitutive rules. In reality, as early as in Speech Acts, Searle himself (1969, p. 224) clearly states that only some constitutive rules have this form, whereas others have a more regulative structure, and that in most cases only the system of constitutive rules has this form. Searle is not alone in this regard. Amedeo Conte (1995, pp. 279-280), for instance, shows clearly with a simple example from chess- "Bishops must move diagonally in chess"- that the process of conceptual constitution of institutional elements involves rules that are clearly regulative in structure.

Not only regulative rules can have a constitutive role, but also seemingly constitutive rules in the "counts as" form can have a distinctively regulative purpose: MacCormick's (1998, p. 334 n. 25) example "Broken bottles count as weapons in pub brawls" is wonderfully simple and explanatory in this regard, because it shows that very often count-as statements are used to explicitly include entities within an already ruleregulated domain. More in general, depending on context, the same statement can serve a constitutive or regulative function: "Well-mannered people do not step onto flowerbeds" can mean that people should not step onto flowerbeds if a sign at the park says so, thus expressing a regulative rule, but the same statement can also be genuinely constitutive of the idea of manners if included in a handbook of etiquette. Given that whether a rule is constitutive depends not on its structure but on its context, the distinction between constitutive and regulative rules is not a structural one between kinds of rules but rather a pragmatic one between different ways of using rules. This leads to a pragmatic conception of constitutive rules: being constitutive is not just a question of semantic content but also of illocutionary force. ${ }^{1}$

Constitutive rules cannot create institutional elements in a completely arbitrary way. Some requirements are formal: constitutive rules must define the conditions for the element to be instantiated in actual practice, but they must also define what the element's normative import is (namely, what consequences an instantiation of that element has in practice) and what kinds of regulations are involved in interacting with that element. For example, chess pieces must be placed on the chessboard in specific

\footnotetext{
1 In Making the Social World, Searle (2010, pp. 96-97) takes the pragmatic route by explaining constitutive rules in terms of "standing declarations.".
} 
positions, but it is also crucial for players to know that all chess pieces can take other pieces, as well as checkmate the king, and to know how those pieces can be moved. Similarly, legal transactions are concluded if specific acts under specific circumstances are performed, but legal transactions are performed because they have consequences in creating obligations and rights for individuals. To use Searle's formula in the way in which it was meant from the outset, namely, as a "useful mnemonic" (Searle \& Smith, 2003, p. 301), it ought to be remembered that constitutive rules must state which $X$ counts as Y, but also which Z is implied by Y: this is Frank Hindriks's "XYZ Formula" (see Hindriks, 2005, pp. 123ff.), by which we can also capture Neil MacCormick's point about the need for "consequential rules" as a complement to "institutive rules." 2

Apart from formal requirements, constitutive rules must also fulfil substantive requirements, and these requirements depend, once more, on the context in which they are used. Rules that are constitutive of a game element must define conditions that players must fulfil and the consequences that are (directly or indirectly) relevant for victory, whereas rules that are constitutive of a legal institution will at least define that institution's relevant conditions of validity within the legal system and the consequences of that validity in terms of rights, powers, and duties of legal subjects. As Schwyzer (1969) has shown, the overall meaning of a system of constitutive rules depends on the broader social practice in which that system is embedded, and that practice sets the conceptual boundaries the constitution of institutional elements must respect: to use an expression by Marmor (2009, chap. 3), the "deep" conventions against whose background surface conventions are framed (see also Lorini, 2000, pp. 263ff., Roversi, 2010 on this).

Given these clarifications about constitutive rules, it follows that my intent is not to defend Searle's view, but rather to show the explanatory relevance of a concept Searle devoted much work to. As mentioned, Searle was not alone in discussing constitutive rules, and this paper is meant as a contribution to this overall line of research. More to the point, I am trying to connect Hart's concept of the internal point of view to the general theory of constitutive rules in social ontology (see also Roversi, 2018). This is a fruitful approach because both sides can gain a lot from this connection. On the one hand, Hart's distinction between an internal and an external point of view on legal norms, as well as his idea that the internal point of view must be explained for a complete understanding of law, provides us with an approach that can be fruitfully extended to the domain of social institutions in general. Indeed, with their insistence on "collective intentionality" or, more generally, on the cognitive underpinnings of institutions, theories of social ontology have provided us with a detailed description of institutional reality from an external point of view, but they have not devoted equal attention to the phenomenological features of that reality seen from an internal point of view. This paper aims to fill this gap. On the other hand, however, Hart failed to appreciate (or at least was ambiguous about) the ontological bearing of his analysis, providing an account of how people talk and behave in relation to social norms but not of how the internal point of view is also a matter of conceiving normative entities, facts, and reality: in this regard, social ontology can complement Hart's approach by

\footnotetext{
2 I will not be dealing with the subtleties of MacCormick's (1986, pp. 52ff.) differentiation between rules of institution-institutive, consequential, terminative - or with Dick Ruiter's elaboration on it (see, for example, Ruiter, 1998), but these, of course, remain essential readings for all theorists of constitutive rules.
} 
providing a description of how social norms can generate social facts, and how institutional practices entail an institutional reality. Being part of an institutional domain is not only a matter of conceiving norms internally, but of living in a domain of abstract, rule-constituted entities with which to interact: this, too, is a general assumption in this paper.

\section{An internal point of view on the ratio of an institution}

I am a professor of legal philosophy, and there are students here in front of me who have come to take a legal philosophy exam. I know that they have registered for this session (appello): In my department, professors set the dates of at least three sessions per term, and there are four terms a year. The sessions must be scheduled in keeping with certain rules: at least fifteen days must pass between two consecutive sessions, and all the sessions must fall within the overall time range the Department of Legal Science has set for the term. The university offers five courses in legal philosophy: four in Italian, one in English. I teach one in Italian and the one in English. I know that the persons gathered here are students in my Italian course because all students whose surname falls within the range $\mathrm{M}-\mathrm{Q}$ are supposed to attend my lectures, will have to take the exam with me, and will receive a final grade from me. Given that I am their professor, they know that I can give them important information about how to gain knowledge in legal theory; they know that I have a duty to teach, to constantly update my own knowledge in the field, and to do research. And they also know that I have passed several exams and was appointed by the university in order to teach here. Of course, they know that this is a university and that they are going through all this effort to earn a law degree from this university, and also that they had to enrol at the university as first-year students and pay the tuition fees charged by the university.

This description reformulates a passage in Making the Social World where Searle (2010, pp. 90-91) illustrates how ubiquitous institutional elements are in our everyday life. But the point here is that I take this reformulated passage to be a description of a legal philosophy exam from an internal point of view in Hart's sense. This is what my student and I know and take for granted when we sit face to face to engage in this practice, which is different from other practices such as drinking a coffee or engaging in conversation. The main difference is that, in this academic practice, the student's knowledge will be tested and I have to be fair in my assessment-hence the student will be a bit nervous and I will stay focused on what he says. All the italicised words in the description denote relevant elements of the situation, and all these elements have something in common: They have a status which is connected with certain normative conditions and consequences. Hence, the internal point of view is populated by an ontology of things that exist and events that happen, and all these things and events are such because they require people to do something in order to instantiate the relevant kinds, and they have consequences on what people may, may not, or must do.

Now, in what follows I will consider three different ways to account for this domain of institutional entities: the constitutive-rules account, the metaphysical-grounding account, and the regulative-rules account. According to the constitutive-rules account, institutions as sets of institutional entities are created by way of rules that are used in a 
constitutive way, namely, as a way to create new kinds of facts, entities, relations, and properties - in short, new things that emerge and populate our world. As mentioned at the beginning, this idea of rules that create new things has seemed suspicious to many, and this is why the other two accounts take direct aim at it. The metaphysical-grounding account claims that no rules are needed to explain the emergence of institutional reality: metaphysical notions are sufficient for this purpose. This means that constitutive rules are irrelevant because deeper, more fundamental, and general notions can account for the same things, as well as for many others. The regulative-rules account, on the other hand, claims that rules are important in explaining institutional reality, but that to this end we need not postulate rules endowed with a magical constitutive power, because ordinary, regulative rules can do the job perfectly well.

Here I will be defending the constitutive-rules account against the other two. In so doing, I will argue that both of the conceptual elements of the notion of constitutive rule - that there are rules and that they have a constitutive role-are necessary to account for institutional reality. Notice that the metaphysical-grounding and the regulative-rules account are complementary in their reductionist approach. The metaphysical-grounding account attacks the very idea that rules are needed to explain institutional reality, while the regulative-rules account attacks the idea that rules can have any constitutive power at all: on the former account, what is constitutive is not rules; on the second, rules are necessary but not constitutive. Hence, if we can convincingly defend the constitutive-rules account against these two kinds of reductionism, we will have shown that neither of the two conceptual elements of the notion of constitutive rules can be explained away, and so that both are at least necessary for a full explanation of institutional reality from an internal point of view. It may be that constitutive rules do not provide us with a complete solution, but they are at least part of such a solution.

Here is my thesis in a nutshell: the two reductionist accounts cannot explain phenomena that can take place and that are perfectly understandable from an internal point of view, that is, they cannot explain normative reactions to the ratio of a given institution. On the other hand, constitutive rules can explain this phenomenon and in that respect are superior to the other two accounts. I will present the relevant phenomenon by way of a case study and then, in separate sections, will explain why the metaphysical-grounding account and the regulative-rules account cannot deal with it properly. In so doing, I will argue that the reason why these two reductionist accounts cannot deal with the case study is precisely that they lack the conceptual features of constitutive rules.

Let us then consider the case study. Mr. Colasanti, a student, has come in for a legal philosophy exam and is sitting in front of me, his professor. We both share the previously described internal point of view to legal philosophy exams. He does not pass the exam, however, and afterward we consider together what went wrong. He tells me that he attended all the classes, but that philosophy is difficult for him because he has no philosophical background. I realize that if I am to give him a fair chance at passing the exam, he would need a week or so of personal assistance, with clarifications and explanations that could eventually amount to a sort of personal course of one to two weeks. I tell him that I do not have time for that. I can give him suggestions and access to teaching materials on the course's website, and I could reply to some of his 
queries. In making this suggestion, I already know that this will not be sufficient for him to form an idea of legal philosophy. He tells me that he needs my help: he will never understand philosophy if I do not help him out. I tell him I have already done my duty and I cannot help all students who come in asking for clarifications on such a sweeping scale. He retorts, "But you are a professor!".

I take this retort by Mr. Colasanti to be perfectly meaningful and genuine, something I must reply to with good arguments. His point is that independently of the formal rules set forth by the university, my being a professor requires me to take his situation into account and do my best to improve his understanding of the subject matter. This is what being a professor means, he is implicitly arguing: it means getting students to understand what is being taught. I insist on my formal duties with him, but for the rest of the day I keep mulling over whether there is something I could do.

I will now try to argue that neither the metaphysical-grounding account nor the regulative-rules account can explain Colasanti's reaction, whereas the constitutiverules account can.

\section{Metaphysical-grounding versus constitutive rules}

The metaphysical-grounding account of institutional reality is here exemplified by Brian Epstein's book The Ant Trap: Rebuilding the Foundations of the Social Sciences, published in 2015. According to Epstein, Searle's notion of constitutive rule is confused and pleonastic and must be replaced with clearer, better-analyzed concepts. This is how he summarizes his view:

In talking about these principles, I am shifting away from Searle's term "constitutive rule" altogether. As we will see, there are many different sorts of principles that give the grounding conditions for social facts. Many of them serve quite different purposes from the ones Searle discusses. The term "constitutive rule" is so closely associated with Searle's formula X counts as $\mathrm{Y}$ in $\mathrm{C}$, that it would be very confusing to retain his term for this much more general notion. Also, the term "constitutive rule" was never a particularly appropriate one. Like the Holy Roman Empire, which was neither holy, nor Roman, nor an empire, constitutive rules are neither constitutive nor are they rules. (Epstein, 2015, p. 77).

The most important concept Epstein appeals to in "rebuilding" (as he says) social ontology is that of "grounding," a concept drawn from contemporary discussions in analytic metaphysics (see Fine, 2012). Grounding is a noncausal but constitutive relation of explanation among facts that is irreflexive, transitive, and asymmetric and is used in metaphysics to deal with relations of existential dependence that are noncausal and synchronic. For example, the fact that I promise my son Carlo to buy him a new videogame is (partly) caused by the fact that he earned very good marks at school this year, but it is grounded in the fact that I uttered the words "OK, I promise I will buy that videogame": I made the promise in virtue of the fact that I uttered some words under certain conditions with a certain intent. Grounding aims to be a genuinely explanatory metaphysical relation, and not simply a modal one like supervenience: it does not simply show relations of covariance but defines an order of fundamentality between 
facts. Hence, in Epstein's view, social facts are grounded in more basic facts: the fact that I am paying a coffee with a one-euro coin is grounded in the fact that I am giving the bartender a distinctive metal disc that to this end has been issued by the Bank of Italy on behalf of the European Central Bank. A set of facts ground a set of social facts in each possible world, but of course these facts can vary depending on the possible world we consider: in some possible worlds, someone can pay for a coffee by uttering a specific formula, or by making a complex gesture. Epstein calls the set of possible worlds in which those social facts are grounded in the same way a frame, and the formula expressing the general grounding relation in that frame a frame principle (see Epstein, 2015, pp. 77-80):

[S]ocial kinds can be instantiated across the universe of different situations, contexts, or worlds. When we set up the conditions for some social fact to obtain, we set up the grounding conditions for that universe. We set up the conditions for it to obtain even in situations, contexts, or worlds where we do not exist. This means we have to generalize from a single situation, context, or world to a universe of possible worlds. A frame is a structure containing this universe, that is, a set of possible worlds in which the grounding conditions for social facts are fixed in a particular way. Each of these possible worlds may have different grounding facts from one another. (For instance, in a different possible world, it is not the piece of paper Billy that was printed by the Bureau of Engraving and Printing, but instead a different piece of paper, Mary.) Different possible worlds, therefore, may have a variety of different social facts. (Epstein, 2015, p. 78).

Grounding relations, as explained by Epstein, are in turn based on facts. The fact that I have one euro is grounded in facts about this metal disc and its history, but-depending on the kind of theory we assume - the general frame principle about how euros are grounded is in its own turn based on facts about collective beliefs, about the sovereign's will, or about correlated equilibria in coordination games. Why do we so frame the act of paying, rather than framing it in some other way? The frame principle is there in virtue of something, something that in Epstein's terminology anchors the frame principle and the corresponding grounding relation (see Epstein, 2015, pp. 80ff.):

It is a general feature of kinds-not just social kinds like dollars and play tea parties - that something needs to glue them together. Even a natural kind like gold may need a bit of "glue," to set it up as a natural kind. Some philosophers hold, for instance, that laws of nature play some role in acting as this glue. [...] The Standard Model [in social ontology] gives us a standard answer about how the social kinds are "glued." They are glued by our ongoing attitudes toward those kinds. Searle and Hume give us different versions of this theory. Recall that in Searle's theory, they are glued together by a very particular fact: the fact The members of the community collectively accept the constitutive rule for the kind. On Hume's theory, they are glued together by the beliefs and practices that put in place a convention about that kind. There are surely other possibilities as well. But all of these theories are theories about a particular relation. They are theories about the "putting in place" relation that holds between a set of facts and the grounding conditions for a kind-in other words, between a set of facts and a frame principle. This is the relation I call anchoring. (Epstein, 2015, pp. 80ff.) 
There is a debate about whether it is advisable to make this distinction between grounding and anchoring. Some hold, for example, that all this structure can be dealt with in terms of nested relations of grounding, and that the notion of anchoring can be dispensed with (Schaffer, 2019; see also Chilovi \& Pavlakos, 2019, pp. 58-59). Epstein, instead, replies that the notion of anchoring is necessary (Epstein, 2019; but see also Epstein, 2015, chap. 9). I will not enter into this debate here, nor will I belabour the distinction. What is important for my purposes is that, in Epstein's view, institutional reality can be explained in terms of metaphysical relations of fundamentality between facts.

Interestingly for the legal philosopher, Epstein applies this model to Hart's theory of law. He does so in Chapter 7 of The Ant Trap, where Hart's structural model of conditions of validity framed by a rule of recognition based on the acceptance of officials is reframed in terms of grounding relations between legally valid facts and grounding conditions and of anchoring relations between this way of framing conditions of validity (the rule of recognition, understood as a frame principle) and facts about collective beliefs and behaviour on the part of citizens and officials. Epstein fruitfully applies his model to legal theory by drawing a distinction between the grounding inquiry, conceived as a distinctively legal enquiry about the correct way in which to frame the sources of law, and the anchoring inquiry, where we would instead locate the most basic legal-theoretical questions about the nature of law and the root of legal systems.

If we apply Epstein's reframing of Hart's model to the previous reconstruction of the internal point of view to exam-taking, we will see that it captures several features of this practice. I am a professor of philosophy of law because I have been appointed by the university and have passed several exams and undergone specific procedures to serve in this role (grounding facts), and this relation is anchored to the overall effectiveness of the Italian legal system, and hence to people's attitudes, beliefs, and dispositions, whether individual or collective. My point, however, is that this reconstruction-which in Hart's terms could be labelled moderately external because it is based on descriptions of facts and relations among facts - cannot account for the case study at hand. Mr. Colasanti's reaction to my being a professor is not a reaction to how best to describe the facts that have cast me in that role, nor is it a reaction to the underlying facts that support the general effectiveness of the legal system: it is not a reaction to facts at all, to what I did in the past that made me a professor. It is instead a normative reaction, a reaction to what I ought to do. My role, in Colasanti's view, is inextricably intertwined with norms.

The point here is twofold. On the one hand, Epstein's model does not explain the normative character of frame principles: frame principles are defined as expressing grounding relations, suggesting that they are inherently descriptive of metaphysical relations, but this dismisses completely the normative character of statements made from the internal point of view. On the other hand, Epstein's model does not explain the normative import of institutional elements, focusing instead on the conditions that put those elements in place. My being a professor is not just a matter of what makes me a professor, but also of what is normatively implied by my acting in that role. This normative part seems to be completely ignored by Epstein's account of law, which ends up resulting in a metaphysical variant of a legal-realistic reading of Hart. 
To be sure, Epstein shows how his framework can account for various conceptions of law, arguing that the most fundamental legal-theoretical debates about the nature of law are debates about what it is that anchors legal rules. Apart from a strictly legal-positivistic reading of Hart, and hence from exclusive legal positivism, he also considers inclusive legal positivism, Dworkinian principlism, and natural law theory. This is indeed a masterful unitary conception, but it assumes that all possible conceptions of law-even the most value-laden ones, like natural law theory and Dworkin's view-ultimately boil down to explanatory relations. However, Mr. Colasanti is not interested in what explains my being a professor. Rather, he wants to press me on what justifies my being a professor. To account for the normative character of Colasanti's reaction, we need a normative notion, and in particular the notion of a rule. This is why the constitutive-rules account grasps something that the metaphysical-grounding account dismisses, namely, that what people react to, from an internal point of view, is norms, not explanatory grounding relations between facts. The relations stated in constitutive rules are normative, not descriptive: constitutive rules do not express or explain that something is the case, as frame principles do, but rather prescribe that that be so. ${ }^{3}$ If I am to become a professor, I am required to complete a certain procedure; if I am a professor, I am required to lecture and I have the power to give grades. While constitutive rules capture the normative character of reactions from an internal point of view, metaphysical grounding reduces those reactions to academic debates, so to speak, about how best to explain a social fact.

It seems to me that this collapsing of normative connections into descriptive explanations lies at the core of the two direct criticisms that Epstein levels at the concept of constitutive rule. The first criticism, in Chapter 9 of The Ant Trap, is set in the context of his reply against "conjunctivism," the idea that the class "grounds" should include anchors. This view, along with the idea that constitutive rules specify the full grounds of institutional elements, is one that Epstein attributes to Searle, and from it he derives the conclusion that constitutive rules lead to an infinite regress. This the structure of regress: if constitutive rules must provide full grounds for an institutional element, they must provide a complete explanation for it; hence collective acceptance of the rule must be included among its grounds; this, however, means that there is a metaconstitutive rule that specifies the full grounds by including collective acceptance of the previous rule among them-but this, too, must be part of the full explanation; hence there must be a meta-meta-constitutive rule that provides the full grounds, and so on (cf. Epstein, 2015, pp. 121-123). From this argument Epstein derives the failure of the idea of a constitutive rule in connection with conjunctivism, and through several other arguments he concludes that anchors must be distinguished from grounds. I will not object to Epstein's attack against conjunctivism, which in many respects seems convincing. However, his regress argument against constitutive rules itself already assumes an explanatory reading of constitutive rules, not a normative one. Constitutive rules do not provide the full grounds for an institutional element, and they couldn't do so; otherwise, they would be completely impractical as rules. Rules do not specify

\footnotetext{
3 The prescriptive aspect of constitutive rules is sometimes denied, often by assuming that constitutive rules are akin to analytical truths and that they cannot be broken. An argument against this view can be found in Roversi 2019. García Carpintero (2021) has recently argued that this is a reason to prefer Williamson's account of constitutive rules over Searle's.
} 
the conditions of their own effectiveness in their statement, because they are meant to regulate interaction with an institutional element rather than provide a full metaphysical explanation of such interaction. What difference can it make to chess players what historical and social processes have led to the existence of the game of chess in our community? Rules are necessary to play, not to understand why the game exists.

This problem of the conditions for the existence of institutional elements is also relevant for Epstein's second direct criticism of constitutive rules. In Chapter 11 of the Ant Trap, Epstein argues that the grounding conditions for the constitution of a group must include facts about the group's existence. For example, the grounding facts for a set of persons to constitute the Supreme Court must include the Supreme Court's existence (cf. Epstein, 2015, pp. 155-156). This, in his view, leads to a "structural flaw in Searle's constitutive rules," because "the facts determining the existence of the Supreme Court—if there are any_are not the same as those determining its constitution":

On Searle's view, what are the grounds for This piece of paper constitutes a dollar? The fact that this piece of paper satisfies the $\mathrm{X}$ conditions. And what are the grounds for That dollar exists? The same fact: that is, that this piece of paper satisfies the X conditions. In other words, embedded in Searle's constitutive rule is the assumption that a social object's existence conditions are exactly the same as its constitution conditions. (Epstein, 2015, p. 161).

In this case, too, Epstein is assuming that the role of constitutive rules is to provide full grounds: he is assuming an explanatory, rather than a normative, role for constitutive rules. Constitutive rules do not need to specify an institution's conditions of existence: that is mainly a historical problem, and very often the original roots of legal institutions are quite vague. Explaining existence is not the point of rules, which regulate an institutional activity rather than providing a full account of its origins, emergence, and persistence. The problems that Epstein raises against constitutive rules can be avoided if we interpret them in light of their purpose as rules, which is to shape the normative features of institutional experience, of the internal point of view taken towards institutions.

Someone could reply to this argument that I am not considering the possibility of a normative grounding relation. However, given that grounding is an explicative relation, the kind of normativity one could possibly identify in it is at most epistemic, whereas the normative structure of institutional elements is normative in a practical sense, where the problem is not how best to understand and explain, but rather to state what needs to happen, or what one needs to do, in order for a specific normative import to obtain. If, on the other hand, grounding relations are conceived as practically normative then, given the constitutive nature of grounding relations of explanation, there is no difference between practically normative grounding and constitutive rules. On this last interpretation, practically normative grounding would amount to nothing but constitutive rules, and the discussion would become merely a question of terminology - only, in this case, I would not see any additional gain in reframing the problem in grounding terms, because an explanation so construed would stand out among other kinds of metaphysical relations, and not for the right reasons: it would come out as an "oddball" explanation. 


\section{Regulative rules plus definitions vs. constitutive rules}

The conclusion from the previous section is that the metaphysical-grounding account cannot capture what is normative about the internal point of view: constitutive rules are in this respect superior, because they already include the constitutive element in the explanatory relation but they are rules, and so normative notions better suited to dealing with phenomena inherent in which is a deontology.

The regulative-rules account, for its part, is framed in terms of rules, so it does not come up against the problem of normativity, but it does face a different sort of problem in comparison with constitutive rules. The regulative-rules account has two main features. First, it assumes that the conceptual content of institutional elements can be reduced to a connection between ordinary, regulative rules. Second, it claims that, apart from this connection between regulative rules, institutional statuses entail nothing more than a terminology, a specific vocabulary that is built to summarize the connection in a concise and more practical way. Hence, on the regulative-rules account, constitutive rules do not constitute anything: there is no institutional realm apart from a set of ordinary rules and a set of stipulative definitions of terms. To constitute is nothing else than to regulate and to stipulate a meaning.

The most important statement of the regulative-rules account is the one that Alf Ross provides in his classic article "Tû-tû," published in the Harvard Law Review in 1957 (the original version was published in 1951). In this article, Ross imagines a tribe of indigenous people (the "Noît-cif" tribe, "fiction" if read in reverse) who believe that a social status exists called $t \hat{u}$-t $\hat{u}$. Members of that community can become $t \hat{u}-t \hat{u}$ under certain circumstances, and their being $t \hat{u}-t \hat{u}$ has certain consequences:

This tribe [...] holds the belief that in the case of an infringement of certain taboos-for example, if a man encounters his mother-in-law, or if a totem animal is killed, or if someone has eaten of the food prepared for the chief-there arises what is called $t \hat{u}-t \hat{u}$. The members of the tribe also say that the person who committed the infringement has become $t \hat{u}-t \hat{u}$. It is very difficult to explain what is meant by this. Perhaps the nearest one can get to an explanation is to say that $t \hat{u}-t \hat{u}$ is conceived of as a kind of dangerous force or infection which attaches to the guilty person and threatens the whole community. For this reason a person who has become $t \hat{u}-t \hat{u}$ must be subjected to a special ceremony of purification. (Ross, 1957, p. 812).

The status $t \hat{u}-t \hat{u}$ is based on a conditional connection between a set of conditions and a set of normative consequences. For example,

If a person has eaten of the chief's food he is $t \hat{u}-t \hat{u}$.

If a person is $t \hat{u}-t \hat{u}$ he shall be subjected to a ceremony of purification.

Ross claims that the term denoting the status means nothing: "It is obvious that the Noît-cif tribe dwells in a state of darkest superstition. 'Th-t $\hat{u}$ ' is of course nothing at all, a word devoid of any meaning whatever. [...] The talk about $t \hat{u}-t \hat{u}$ is pure nonsense" (ibid.). What lies behind this void term is nothing but a complex set of conditional regulative rules connecting conditioning facts with normative consequences. This amounts to a reduction of the institutional status to a more basic explanation: 
Of course it would be possible to omit this meaningless word altogether, and instead of the circumlocution:

(1) He who kills a totem animal becomes $t \hat{u}-t \hat{u}$;

(2) He who is $t \hat{u}-t \hat{u}$ shall undergo a ceremony of purification, to use the straightforward statement:

(3) He who has killed a totem animal shall undergo a ceremony of purification. (Ross, 1957, pp. 816-817).

Now, according to Ross this analysis can be extended to legal concepts in general: "our legal rules are in a wide measure couched in a ' $t \hat{u}-t \hat{u}$ ' terminology." Legal concepts refer to a connection between rules: they simply summarize rules for practical purposes. This is how, for example, Ross proposes to analyze the concept of property:

The legal rules concerning ownership could, without doubt, be expressed without the use of this term. In that case a large number of rules would have to be formulated, directly linking the individual legal consequences to the individual legal facts. For example:

If a person has lawfully acquired a thing by purchase, judgment for recovery shall be given in favor of the purchaser against other persons retaining the thing in their possession.

If a person has inherited a thing, judgment for damages shall be given in favor of the heir against other persons who culpably damage the thing.

If a person by prescription has acquired a thing and raised a loan that is not repaid at the proper time, the creditor shall be given judgment for satisfaction out of the thing.

If a person has occupied a res nullius and by legacy bequeathed it to another person, judgment shall be given in favor of the legatee against the testator's estate for the surrender of the thing.

If a person has acquired a thing by means of execution as a creditor and the object is subsequently appropriated by another person, the latter shall be punished for theft.

An account along these lines would, however, be so unwieldy as to be practically worthless. (Ross, 1957, p. 819).

The reductionistic import of this approach is apparent and fits very well with Ross's legal realism. If all legal notions can be reduced to a connection between conditions and normative consequences, and hence to conditional rules, then legal terms referring to institutions of law do not have a meaning and do not refer to anything apart from rules-hence there is no legal reality, no legal facts or entities, but only a vocabulary that summarizes a discipline in terms of rules. This vocabulary can very well have practical purposes, but apart from that it is void: even though it seems to denote objective entities, in reality it does not. Hence, even though Ross does not make any explicit reference to the concept of constitutive rule in this work (he will discuss rules of chess at length in his 1968 Directives and Norms: Ross, 1968, p. 53), he clearly attacks the idea underlying that notion, namely, that there can be a domain of institutional elements constituted through rules that can be referred to by way of institutional terms. 
It is interesting to note that an argument very similar to that put forward by Ross has recently been put forward in social ontology by Frank Hindriks and Francesco Guala with specific reference to constitutive rules. In Hindriks and Guala's view, institutions can be analyzed in terms of game-theoretic correlated equilibria where correlation devices are used. Their example is the same as the one discussed by Ross, namely, property:

In a nutshell, the rules represent equilibria (or parts of equilibria) and help the players to exploit a particular correlation device. Let us see how this account works in the simple case of property. Recall that the players (P1 and P2) use pre-emption as a correlation device. The correlated equilibrium in the game of property is the pair of strategies:

(s1) Use if P1 occupied first, do not use if P2 occupied first.

(s2) Use if P2 occupied first, do not use if P1 occupied first. (Hindriks \& Guala, 2015, 468).

These rules are regulative rules, in Searle's language, and for simplicity they can be summarized by means of a single principle:

[R] If one is the first to occupy a piece of land, one has the right to its exclusive use.

Notice that this rule does not include a label for or name of the institution. Suppose we now introduce the term "property $*$ " as follows: we say that what it takes for a piece of land to become someone's property $*$ is that she is the first to occupy it. Furthermore, we say that what it is or means for a piece of land to be someone's property $*$ is that she has the right to its exclusive use. By so doing we have split the regulative rule in two parts and used the term "property $*$ " to turn these parts into complete sentences: the first one says that a piece of land is the property $*$ of the person who is the first to occupy it; the second one that if a piece of land is someone's property $*$, she has the right to its exclusive use. Another way to put it is that we have transformed the regulative rule $[R]$ in two rules, $[\mathrm{B}]$ and $[\mathrm{S}]$, respectively:

[S] If a piece of land is someone's property $*$, she has the right to use it.

Now, the combination of these two rules forms a constitutive rule:

[C] If a person first occupies a piece of land then it is her property $*$, and if a piece of land is someone's property $*$ then she has the right to use it. (Hindriks \& Guala, 2015, p. 472).

Given this framework, Hindriks and Guala argue that constitutive rules simply introduce a terminology to summarize the complex set of regulative rules making up the institution: regulative rules can be transformed into constitutive rules by introducing terms. Similarly to Ross, they recognize that this operation has an important practical purpose ("Transforming a regulative rule by introducing institutional terms such as 'owner $*$ ' or 'property $*$ ' is very convenient [...] the representation of the equilibrium in symbolic form has the advantage of cognitive economy": Hindriks \& Guala, 2015, p. 473), but in the end their approach is reductionistic. Just as regulative rules can be transformed into constitutive rules by introducing a terminology, the latter can always be transformed into the former if we are ready to give up the need for a terminology: 
"In the end, constitutive rules are nothing but (systems of) regulative rules augmented by the introduction of theoretical terms." 4

Unlike the metaphysical-grounding account, the regulative-rules account is well equipped to explain the normative character of Mr. Colasanti's reaction. Mr. Colasanti has internalized the rules defining the conditions and the consequences of being a professor, and he is not interested in explaining that status but in the duties that are connected with it. Clearly, Mr. Colasanti is adopting an internal point of view: he considers the rules as standards of conduct, taking them as possible grounds for justification, and he reacts to what he perceives to be my deviation from them. Here Ross, Hindriks, and Guala would say that this point of view that he is taking is internal to the regulative rules that professors must follow-it is not internal to constitutive rules, because constitutive rules are nothing but regulative rules plus the word professor. Hence, as proponents of the regulative-rules account would argue, an appeal to the internal point of view does not entail an argument in favour of constitutive rules.

I concede that the regulative-rules account can explain the normative character of Mr. Colasanti's reaction, and also that a significant part of the rules he adopts and defends, even most of these rules, are regulative in nature. The problem, however, is that Mr. Colasanti's reaction is not about the rules: none of the rules the example calls into play would require me to support Mr. Colasanti in the way he is asking me. On the regulative-rules account, I could simply reply to him that what he is saying is meaningless, because the very meaning of the term professor is a composition of rules, none of which requires me to do what he is asking. But his reaction is not meaningless. His argument is precisely that, even recognizing that there is no rule requiring me to support him beyond class time and office hours, a rule of this kind should be added to the list and be made explicit, given the overall ratio of the institutional role "being a professor." But this entails that the meaning of professor is not simply a set of conditional regulative rules. To state the point more directly: if one can always build a meaningful argument about changing or adding further rules connected with a status in view of that status's purpose or underlying rationale, the concept of that status cannot simply be reduced to the regulative rules that are connected with it. There is at least one other element of meaning apart from the rules, and this element is the overall rationale behind the connection between conditions and normative consequences- the purpose the institution is built for, one might say. If this further element were not part of the picture, any connection, any arbitrary set of rules could do. Hence, even though the regulative-rules account can explain the normative character of Mr. Colasanti's reaction, it cannot explain the fact that his normative reaction is not about the actual rules but about changing the rules in view of the overall purpose that professors are meant to serve in the framework of a university.

Proponents of the regulative-rules account could reply that this appeal to the institution's ratio amounts to nothing else than a concealed moral claim. Colasanti's point, they could say, is simply about how to better change the rules in view of a moral evaluation of them, and this confirms that there is nothing more than regulative rules involved in the picture: on the one hand legal regulative rules about what professors

\footnotetext{
4 The idea that constitutive rules simply introduce a terminology can also be connected with Riccardo Guastini's view that constitutive rules are nothing but stipulative definitions: see, for example, Guastini (1983, p. 167).
} 
should do, on the other hand moral regulative rules about what good persons should do. But Colasanti's reaction is not simply a moral reaction: he is not arguing about what I should do to be a good professor or a good person. Rather, he wants to argue that I have an institutional duty to find a way to help him understand. His reaction, then, is all internal to the institution's normative framework: it does not invoke any broader moral evaluations. Similarly, my worry is not about whether, in replying so formally to him, I acted without compassion, but rather whether I acted unprofessionally.

This situation exemplifies something that can happen, and indeed very often does happen, in the institutional domain. This is the situation where people debate about how best to interpret, not the rules connected with a given institution, but rather the ratio, the underlying rationale, of the institution itself. People involved in this debate are internal to the institution in the deepest sense: they do not simply accept the rules but also embrace the underlying axiology and teleology of those rules and passionately defend their view about how best to conceive them. This interpretive debate is inherently dynamic, because the rules in this case are not seen as something fixed but as something that can be changed in light of the institution itself. In a sense, the institution has a standing independent of the actual rules, and it can generate new rules or new interpretations of old rules on the basis of its ratio. In law, this kind of reasoning is ubiquitous. New regulations are generated by analogy on the basis of the ratio of old ones, even though they clearly do not follow from the letter of the provisions. Extensive interpretations of provisions are generated in terms of the underlying ratio, with the assumption that the legislature "stated less than what it wanted" (minus dixit quam voluit). Expansive interpretations of constitutional provisions are generated to account for new rights and to expand the perimeter of old ones. All these are cases of legal reasoning from a standpoint that is completely internal: given an institution's rationale, can we - that is, are we allowed by the system to-apply a similar framework to a new, unregulated case? Can we interpret the letter of the rules in a more liberal way to account for an unexpected variant of the rule-governed behaviour? Should we - that is, does the constitution require us to-interpret a general clause of equal treatment among citizens to apply to new problems like same-sex marriage, or to migrants, refugees, and other kinds of noncitizens? These questions are part of the normal life of an institution. And all these questions, like Colasanti's point, depart from the formal letter of provisions and go directly to an institution's underlying ratio. This need to refer to an institution's underlying rationale shows that the institution has a certain degree of independence from its actual rules, and this is exactly the sense in which I take constitutive rules to be constitutive: they create something which acquires objectivity. Constitutive rules frame a status that forms the background against which to debate whether, and how, to change the institution's current rules. They do regulate, to be sure, defining how people must behave to obtain a certain normative outcome from the status. But this regulating work they do serves a point or purpose-one that is essential to the institution's underlying ratio - and the rules can accordingly be amended to better fit that purpose: the rules, therefore, do not exhaust the whole thing.

"But why do we need to refer to an independent thing?", a proponent of the regulative-rules account might ask: "Why can't we explain Colasanti's reaction simply 
in terms of the ratio of regulative rules?" Unlike Ross, Hindriks and Guala are not eliminativist about institutions: in their view, institutions exist and they have both an etiological function (solving coordination problems) and a teleological one (achieving social values) (see Hindriks \& Guala, 2021). Only, institutions consist of regulative rules. Hence, in a possible objection to my argument, it could be said that Colasanti is simply referring to the teleological function of the regulative rules about professors rather than to the ratio of the role of professor as something distinct from those rules. The idea that institutions have a rationale is not inherently inconsistent with the idea that they are made up only of regulative rules.

This is a good point, but I would note in reply to it that an independent status is something we construct in framing the rules rather than after the fact: this status is not a mere ex post hypostatization. In the theory of legal interpretation, the concept of ratio-of a provision's underlying rationale - is connected with the idea of legislative intent: the idea is that the legislature enacted the provision with a purpose in mind. Any legal enquiry into legislative intent, however, proceeds from an idealized conception of the legislature, which is taken as an entity that is aware of the factual context, has full knowledge of the legal system and its complexities, and wants that system to be coherent. This means that ratio is a hybrid concept, certainly pointing to the concept of purpose and of a set of underlying values, but also to the idea of a system: rules need to be considered in light of the purpose they serve, the values they advance, and the unitary meaning they convey along with other rules. So, if we only consider the ratio of the regulative rules about professors in isolation from their underlying status, we end up losing our understanding of the way in which those rules are connected. Consider the rules about bishops in chess. The ratio of these rules, taken individually, is very similar to that of the rules regulating other pieces in the game: "Bishops must move diagonally," for example, has the purpose of limiting the movement of bishops in a way that can be interesting for players. Under this interpretation, however, all rules governing the movement of chess pieces would have the same ratio: to frame this movement in such a way as to make for a balanced and challenging game. Only when we take it that those pieces are meant to be different, and that each has a peculiar role in the game, more or less powerful, more or less significant - only when we conceive of chess as a system of entities - can we understand the ratio for all the different pieces and then the specific rationales behind each rule that apply to a given piece. This makes it possible, moreover, to change or adapt the game when needed: I know that the queen is meant to be the most powerful piece, or that the pawns are meant to be expendable, and I can therefore take these aspects into account when reframing particular aspects of the game (as often happened over the long history of chess). As Bartosz Brożek has argued in discussing Ross, not only do institutional concepts make for greater coherence in a set of rules, they also bear an important heuristic value:

Let us assume that in some legal system there exist only rules pertaining to the ownership of movable and immovable things, and the legislator must consider the introduction of a new set of rules regulating intellectual property. It is clear that the existing concept of ownership is useful in such an endeavour. The

\footnotetext{
${ }^{5}$ I am thankful to an anonymous reviewer for raising this point.
} 
legislator does not have to devise a completely new system of norms for intellectual property, but instead works within the framework of the existing model of ownership, only adapting it to the peculiar character of the problem under consideration. (Brożek, 2016, p. 21).

In this and other cases, rules are modified or adapted in light of the institutional concept, which means that the concept is not the result of a trivial derivation from the rules - and that, in a nutshell, is the important point about constitutive rules being something different from a mere summary of regulative rules. When a system of rules has a constitutive role, it populates the social world with a new entity with which people can, and in some cases must, interact. We cannot reduce that entity to a mere device by which to regulate behaviour, for the simple reason that the rules constructed to that end are at the same time designed to be coherent with the entity itself: they do not make up the entity but rather depend on what the entity is meant to do. Ownership can have different rules in different legal systems, yet the institution is taken to be the same across these systems and to be commensurable because the different rules serve a similar ratio, namely, to make it possible for legal persons to have something at their exclusive disposal. If the constitutive rules of property in a legal system were simply regulative, the institutions of property in different systems could not be recognized as structurally modified instances of the same institution but would have to be considered altogether different entities. In fact there is an underlying coherence to the regulative rules, which depend on the role that in our legal culture is played by the institution of property as something which has an independent standing. In the course of the history of law, property has existed as an institution with a social purpose, and it is this purpose that we take into account when discussing whether it is worth adding new rules or modifying them, or whether we share the same institution with other cultures, or how to compare and contrast different instances of them in view of their effectiveness and development. This is what Mr. Colasanti had in mind in making his point about professors.

Yet the idea of institutional entities having an independent standing and being constituted as something with their own objectivity can still seem suspicious- the outcome of a hypostatization. What are these things that constitutive rules create? How can they in some sense be real? This is the kind of scepticism that constitutive rules have always raised, in their supposed magical power to create a separate reality, and it is what has prompted the construction of competing reductionistic accounts like the metaphysical-grounding and the regulative-rules account. As a consequence, a full defence of constitutive rules should at least give some clues about how these doubts might be answered. What kind of "special" metaphysic can a proponent of constitutive rules come up with to ground their wizardry?

What I suggest is that we need not posit any special kind of entities behind constitutive rules: they can simply be traced to the ordinary ability of human beings to construct artifacts. ${ }^{6}$ One of the distinctive features of human beings is that they can, and do, create artifacts that have functional properties and are organized into kinds, and since the rise of homo sapiens some of these artifacts have been symbolic. Their

\footnotetext{
6 This proposal is rooted in the so-called artifact theory of law, developed in Crowe (2014), Burazin (2016), Ehrenberg (2016), Roversi (2016) and Burazin et al. (2018).
} 
meaning, in other words, was something more than their mere physical appearance, and was so in virtue of a shared recognition: "Let us (together) make it so that this $\mathrm{X}$ is a Y, and that with Y come these consequences." This mechanism of make-believe was one of the cognitive underpinnings of the behavioural modernization of the genus homo and is one of the key features of collective activity that children understand since age five (Rakoczy, 2007; Rakoczy \& Tomasello, 2007; see also Roversi, 2021). When generalized and applied to important purposes within the community, these shared principles become entrenched and protected by strong normative support: they become rules in a full practical sense. And these rules are constitutive, because through them we create symbolic artifacts with which members of the community must interact: We build a shared immaterial entity and define its interaction plan in terms of rules. $^{7}$ These artifacts are there for a reason, a social purpose, and their rules can be modified and interpreted in terms of this purpose. This purpose can change. Hence, as a community develops, these artifacts come to have a history of interpretations and re-interpretations - a deliberative history that explains what these artifacts are and what their role is. Debating the role of institutional artifacts and reframing their rules is an interpretive endeavour that has important social and political implications. Once debated, these institutional artifacts are given a new shape, either by agreement or by authoritative fiat, but knowledge of the artifact's deliberative history is an important factor for defining some grounds for objectivity within them. We create artifacts by way of rules; then rules will have to be modified in light of the artifact's evolving concept.

\section{Conclusion: constitutive rules and institutional artifacts}

The conclusion of my argument can be summarized as follows. From an internal point of view, we can observe meaningful normative reactions to an institution's ratio- to its point or purpose - as something different from its operating rules. This shows that there is a normativity to institutions, and that they can accordingly have a standing that is partly independent of their current regulation. This is a feature of institutions that I think cannot be ignored, and one that the constitutive-rules account captures better than the metaphysical-grounding account or the regulative-rules account. Constitutive rules are rules, and so can account for the normative character of the reaction in a way the metaphysical-grounding account cannot; and they are constitutive, so they can account better than regulative rules for the fact that the normative reaction in question is not about the actual rules but about the purpose of the institution, whose standing is partly independent of its contingent regulation.

The phenomenon I have tried to explain in this paper can be fruitfully connected with at least two conceptions in contemporary social ontology: Åsa Andersson's concept of "telic normativity" and Sally Haslanger's notion of a "target concept." Andersson argues that statuses can be connected with a sort of normativity that is not captured by

\footnotetext{
7 The view that by way of constitutive rules members of a community create institutional artifacts does not entail that all institutions are created by authority or defined by way of stipulation. This, of course, is a typical way in which institutions come into being, but many institutional structures instead emerge through the force of custom, as the outcome of behavioural regularities.
} 
rule-constituted deontic powers, and among the examples she brings in support of her view is the same one as that of professors discussed in this paper. Her idea is that "the social world consists of ideals" and that "many functions are defined in terms of goals or purposes, rather than in terms of rights and obligations." Given that "an ideal connected to the role of being a professor is to publish high quality work, work that goes beyond what is merely required, [...] reasons deriving from this ideal might conflict with her administrative obligations" (Andersson, 2007, pp. 97-98). That is precisely my point, but Andersson seems to derive from it precisely the opposite conclusion than mine: constitutive rules do not exhaust the normativity of the institutional status, because they define deontic powers, and telic normativity is not a kind of deontic power. On the contrary, I argue that this is precisely why constitutive rules are constitutive: they do not simply define powers but also, and in the first place, create the concept of an independent abstract artifact with inherent purposes and values, in light of which the rules themselves can be modified and amended.

Haslanger, on the other hand, argues for a possible detachment between the "manifest" concept of a given institutional notion, its "operative" concept as shown in the actual social practice, and a "target" concept that is "the concept that, all things considered (my purposes, the facts, etc.), I should be employing" (Haslanger, 2012, p. 388). ${ }^{8}$ Given this framework, my argument could be restated as follows: Mr. Colasanti is directing me toward the target concept "professor," urging me to go beyond the mere rule-bound, manifest concept. As in Andersson's case, I take this to be an argument not against constitutive rules but in support of them. If rules are constitutive and not merely regulative, it is perfectly possible that the ratio for the status they create becomes constitutive of its concept over and beyond the contingent features resulting from the way the concepts is regulated. This opens the possibility for the processes of amelioration that Haslanger calls for, which processes, in her view, do not amount to reconceptualizing the social concepts under scrutiny but are rather processes of discovery, making it possible to find the best potential for those concepts. It is perfectly possible to so describe not only my case study but also, for example, any kind of expansive interpretation of the constitutional framework - an undertaking that requires us to take a deep internal point of view to the legal system. This is Mr. Colasanti's point, and this fits in well with my argument in support of constitutive rules.

This concludes my defence of constitutive rules. My point was that the idea of rules through which we create institutional artifacts having an independent standing is a key assumption of social ontology, and that constitutive rules capture this idea better than other competing accounts. This certainly does not mean that the notion is inevitably implied by any proper socio-ontological account: a broader notion, capable of doing more explanatory work, could replace the notion of constitutive rule in a more elegant way. What I have tried to argue, however, is that any such broader notion-and in the end any complete socio-ontological explanation-will have to at least include the two

\footnotetext{
${ }^{8}$ I am extremely thankful to an anonymous reviewer for pointing out this possible connection to me.
} 
main elements that I take to be essential to the concept of constitutive rules, namely, the idea of creating something and the idea of doing so by way of rules.

Funding Open access funding provided by Alma Mater Studiorum - Università di Bologna within the CRUI-CARE Agreement.

Open Access This article is licensed under a Creative Commons Attribution 4.0 International License, which permits use, sharing, adaptation, distribution and reproduction in any medium or format, as long as you give appropriate credit to the original author(s) and the source, provide a link to the Creative Commons licence, and indicate if changes were made. The images or other third party material in this article are included in the article's Creative Commons licence, unless indicated otherwise in a credit line to the material. If material is not included in the article's Creative Commons licence and your intended use is not permitted by statutory regulation or exceeds the permitted use, you will need to obtain permission directly from the copyright holder. To view a copy of this licence, visit http://creativecommons.org/licenses/by/4.0/.

\section{References}

Andersson, Å. (2007). Power and social ontology. Bokbox Publications.

Brożek, B. (2016). On Tû-tû. Revus: Journal for Constitutional Theory and Philosophy of Law, 27, 15-44.

Burazin, L. (2016). Can there be an artifact theory of law? Ratio Juris, 29, 385-401.

Burazin, L., Himma, K. E., \& Roversi, C. (Eds.). (2018). Law as an artifact. Oxford University Press.

Chilovi, S., \& Pavlakos, G. (2019). Law-determination as grounding: A common grounding framework for jurisprudence. Legal Theory, 25, 53-76.

Conte, A. G. (1995). Paradigmi di analisi della regola in Wittgenstein. In Id., Filosofia del linguaggio normativo. II. Giappichelli. (1st ed. 1983.)

Crowe, J. (2014). Law as an artifact kind. Monash University Law Review, 40, 737-757.

Ehrenberg, K. M. (2016). The functions of law. Oxford University Press.

Epstein, B. (2015). The ant trap: Rebuilding the foundations of the social sciences. Oxford University Press.

Epstein, B. (2019). Anchoring vs. grounding: Reply to Schaffer. Philosophy and Phenomenological Research, 99, 768-781.

Fine, K. (2012). Guide to ground. In F. Correia \& B. Schneider (Eds.), Metaphysical grounding: Understanding the structure of reality (pp. 37-80). Cambridge University Press.

García-Carpintero, M. (2021). How to understand rule-constituted kinds. Review of Philosophy and Psychology. https://doi.org/10.1007/s13164-021-00576-z

Guastini, R. (1983). Cognitivismo ludico e regole constitutive. In U. Scarpelli (Ed.), La teoria generale del diritto: Problemi e tendenze attuali. Studi dedicati a Norberto Bobbio (p. 153ff.). Comunità.

Haslanger, S. (2012). Resisting reality: Social Construction and social critique. Oxford University Press.

Hindriks, F. (2005). Rules and institutions: Essays on meaning, speech acts and social ontology. Haveka BV.

Hindriks, F., \& Guala, F. (2015). Institutions, rules, and equilibria: A unified theory. Journal of Institutional Economics, 11, 459-480.

Hindriks, F., \& Guala, F. (2021). The functions of institutions: Etiology and teleology. Synthese, 198, 2027-2043.

Lorini, G. (2000). Dimensioni giuridiche dell'istituzionale. CEDAM.

MacCormick, N. (1986). Law as institutional fact. In N. MacCormick \& O. Weinberger (Eds.), An institutional theory of law (p. 49ff.). Kluwer.

MacCormick, N. (1998). Norms, institutions, and institutional facts. Law and Philosophy, 17, 301-345.

Marmor, A. (2009). Social conventions: From language to law. Princeton University Press.

Ross, A. (1957). Tû-tû. Harvard Law Review, 70, 812-825.

Ross, A. (1968). Directives and norms. Routledge \& Kegan Paul.

Rakoczy, H. (2007). Play, games, and the development of collective intentionality. New Directions for Child and Adolescent Development, 115, 53-67. 
Rakoczy, H., \& Tomasello, M. (2007). The ontogeny of social ontology: Steps to shared intentionality and status functions. In S. L. Tsohatzidis (Ed.), Intentional acts and institutional facts (p. 113ff). Springer.

Roversi, C. (2010). Constitutive rules in context. Archiv Für Rechts- Und Sozialphilosophie, 96, $223-238$.

Roversi, C. (2016). Legal metaphoric artifacts. In J. Stelmach, B. Brozek, \& L. Kurek (Eds.), The emergence of normative orders (p. 215ff). Copernicus Center Press.

Roversi, C. (2018). Constitutive rules and the internal point of view. Argumenta: Journal of Analytic Philosophy, 4, 139-156.

Roversi, C. (2019). Six heresies on constitutive rules. Diritto e Questioni Pubbliche, 2, 1-25.

Roversi, C. (2021). Cognitive sciences and the nature of law. In B. Brożek, J. Hage, \& N. A. Vincent (Eds.), Law and mind (p. 99ff). Cambridge University Press.

Ruiter, D. W. P. (1998). Structuring legal institutions. Law and Philosophy, 17, 215-232.

Schaffer, J. (2019). Anchoring as grounding: On Epstein's The ant trap. Philosophy and Phenomenological Research, 99, 749-767.

Schwyzer, H. (1969). Rules and practices. The Philosophical Review, 78, 451-467.

Searle, J. R. (1969). Speech acts: An essay in the philosophy of language. Cambridge University Press.

Searle, J. R., \& Smith, B. (2003). The construction of social reality: An exchange. American Journal of Economics and Sociology, 62, 285-309.

Searle, J. R. (2010). Making the social world: The structure of human civilization. Oxford University Press.

Publisher's Note Springer Nature remains neutral with regard to jurisdictional claims in published maps and institutional affiliations. 